\title{
Cross-regulation between protein L-isoaspartyl 0 -methyltransferase and ERK in epithelial mesenchymal transition of MDA-MB-231 cells
}

\author{
Jiyeon RYU, Jihyeok SONG, Jieun HEO, Yongwoo JUNG, Sang-Jin LEE, Sungyoul HONG*, Jae Youl CHO* \\ Department of Genetic Engineering, Sungkyunkwan University, Suwon 440-746, Korea
}

\begin{abstract}
Aim: Protein L-isoaspartyl O-methyltransferase (PIMT) regulates cell adhesion in various cancer cell lines through activation of integrin $\alpha$ v and the PI3K pathway. The epithelial mesenchymal transition (EMT) enables epithelial cells to acquire the characteristics of mesenchymal cells, and to allow them to migrate for metastasis. Here, we examined the relationship between PIMT and EMT with attached or detached MDA-MB 231 cells.

Methods: Human breast cancer cell line MDA-MB-231 cells were maintained in a suspension on poly-HEMA in the presence or absence of PIMT siRNA or ERK inhibitor PD98059. The mRNAs and proteins were analyzed using RT-PCR and immunoblotting, respectively.

Results: During cellular incubation under detached conditions, PIMT, integrin $\alpha$ v and EMT proteins, such as Snail, Slug and matrix metalloproteinase 2 (MMP-2), were significantly increased in correlation with the phosphorylation of ERK1/2. The ERK inhibitor PD98059 (25 $\mathrm{\mu mol} / \mathrm{L})$ strongly suppressed the expression of the proteins and PIMT. Interestingly, PIMT siRNA blocked the phosphorylation of ERK and the expression of the EMT proteins. Additionally, PIMT and ERK phosphorylation were both co-activated by treatment with TGF- $\beta$ (10 ng/mL) and TNF- $\alpha(10 \mathrm{ng} / \mathrm{mL})$.

Conclusion: A tight cross-regulation exists between ERK and PIMT in regards to their activation and expression during the EMT.
\end{abstract}

Keywords: protein L-isoaspartyl O-methyltransferase (PIMT); breast cancer; metastasis; epithelial mesenchymal transition; extracellular signal-regulated kinase (ERK); siRNA

Acta Pharmacologica Sinica (2011) 32: 1165-1172; doi: 10.1038/aps.2011.94; published online 15 Aug 2011

\section{Introduction}

The epithelial mesenchymal transition (EMT) is an essential component of tumor progression and also plays a normal role in embryonic development, tissue remodeling and wound repair $^{[1]}$. The occurrence of the EMT during tumor progression allows benign tumor cells to acquire three major changes in cellular phenotype. These include morphological changes from the cobblestone-like morphology of epithelial cells into spindle-shaped mesenchymal cells, changes in differentiation markers, where cytokeratin intermediate filaments become vimentin filaments, fibronectin or certain integrins, and the conversion of stationary cells to motile cells capable of invading through the extracellular matrix $(\mathrm{ECM})^{[2,3]}$. The breakdown of epithelial cells that ultimately leads to aggressive cancer progression is correlated with a loss of epithelial characteristics and the acquisition of a migratory phenotype ${ }^{[4]}$.

\footnotetext{
* To whom correspondence should be addressed.

E-mail jaecho@skku.edu (Jae Youl CHO); syhong@skku.edu (Sungyoul HONG)

Received 2011-01-13 Accepted 2011-06-08
}

In addition to reorganization through translocation during metastasis, additional aspects of EMT biology, such as resistance to anoikis, enhanced survival, genomic instability, and resistance to chemotherapies, have also been recently identified $^{[5]}$.

Protein $L$-isoaspartyl O-methyltransferase (PIMT, EC2.1.1.77) is a widely distributed enzyme that catalyzes the transfer of an active methyl group from $S$-adenosyl- $L$-methionine (SAM) to the a-carboxyl group of atypical $L$-isoaspartyl and $D$-aspartyl residues that are generated during the aging process. This enzyme does not catalyze this transfer to normal $L$-aspartyl residues contained in peptides or proteins ${ }^{[6,7]}$. The functional role of PIMT in cancer cell migration has not been clearly elucidated. The reduced motility of cells on aged type-I collagen has been shown to be alleviated by PIMT-treated repaired collagen by up to $72 \%{ }^{[8]}$. It is thus clear that the detachment and attachment of tumor cells can be regulated by PIMT expression. Furthermore, functional activation of integrins and integrin binding to fibronectin- $\mathrm{I}_{5}$ has been reported to regulate PIMT expression and to be relevant in the formation of isoaspartyl residues in the extracellular matrix ${ }^{[9]}$. 
Because the role of PIMT in the EMT and metastatic processes remains unclear, in this study, we explored the involvement of PIMT in the regulation of the detachment and attachment of the anoikis-resistant cell line MDA-MB-231, an aggressive breast cancer cell line with a highly invasive, migrative, and metastatic characters ${ }^{[10]}$, by culturing the cells in poly-HEMA (2-hydroxyethylmethacrylate)-coated dishes and introducing siRNA specific for PIMT.

\section{Materials and methods Materials}

$\mathrm{LiCl}$ and poly-HEMA were purchased from Sigma-Aldrich (St Louis, MO, USA). Dulbecco's modified Eagle's medium (DMEM), penicillin/streptomycin solution (10000 unit/mL and $10 \mathrm{mg} / \mathrm{mL}$, respectively), fetal bovine serum (FBS) and Dulbecco's phosphate-buffered saline (DPBS) were purchased from Gibco BRL (Gaithersburg, MD, USA). MDA-MB 231 cells were obtained from American Type Culture Collection (Manassas, VA, USA). Moloney murine leukemia virus (M-MLV) reverse transcriptase, polymerase chain reaction (PCR) premix, and Sapphire Super Taq were purchased from Rexgene Biotech Co, Ltd (Ochang, Korea). All primers used for PCR were purchased from Bioneer (Taejeon, Korea). A mixture of Stealth ${ }^{\mathrm{TM}} /$ siRNA duplex oligoribonucleotides against PIMT and Lipofectamine ${ }^{\mathrm{TM}}$ RNAiMAX was purchased from Invitrogen (Carlsbad, CA, USA). Rabbit anti-PIMT antiserum was produced against recombinant PIMT proteins of porcine brain as previously described (Koh and Hong, unpublished data). Antibodies against MAPK, MMP-2, MMP-9, $\mathrm{N}$-cadherin, integrin av, phospho-GSK3 $\left(\mathrm{Tyr}^{279 / 216}\right)$, phosphoERK1/ 2 (Thr $\left.{ }^{202} / \mathrm{Tyr}^{204}\right)$, phospho-MEK1 $\left(\operatorname{Ser}^{218 / 222}\right) / \mathrm{MEK} 2$ $\left(\operatorname{Ser}^{222 / 226}\right)$, phospho-Akt1/PkBa (Ser ${ }^{473}$ ) and phospho-p90RSK $\left(\operatorname{Ser}^{380}\right)$ were obtained from Millipore (Bedford, MA, USA). $\beta$-actin antibody was obtained from Santa Cruz Biotechnology (Santa Cruz, CA, USA). The ERK kinase inhibitor PD98059 was purchased from CalBiochem (La Jolla, CA, USA).

\section{Cell culture}

MDA-MB 231 cells (poorly differentiated adenocarcinoma, grade III), a human breast cancer cell line, appearing phenotypically as spindle shaped cells exhibiting highly invasive phenotype $^{[10,11]}$ and differentiation markers such as E-cadherin and keratin, $\beta$-catenin, and vimentin ${ }^{[12]}$, were grown in DMEM with $10 \%$ fetal bovine serum and $1 \%$ penicillin/streptomycin at $37^{\circ} \mathrm{C}$ in a humidified atmosphere under $5 \% \mathrm{CO}_{2}$. Cells were collected and passaged using a $0.05 \%$ trypsin- $0.02 \%$ ethylenediamine tetra-acetic acid (EDTA) solution, and cell counts were performed in triplicate using a hemocytometer.

\section{Quantitative analysis of EMT}

Detached (d) MDA-MB-231 cells $\left(10^{6}\right.$ cells/well $\times 6$ wells) were maintained in suspension on poly-HEMA or were allowed to attach (a) to culture dishes in serum-free media for $24 \mathrm{~h}$. The cells were then treated with $0.025 \%$ trypsin/ $0.02 \mathrm{mmol} / \mathrm{L}$ EDTA and re-attached to the culture plates. The images were taken by a digital camera at the indicated time after seeding.
The numbers of round and total cells were counted in a hemocytometer, as reported previously ${ }^{[13]}$. The percentage of cells morphologically changed was determined by the following equation: \% of cells in aggregates $=[$ (total cells-round cells) $/$ total cells] $\times 100$. All values, expressed as mean \pm SEM, were obtained from 3 to 6 replicate cultures.

\section{Reverse transcriptase-polymerase chain reaction analysis}

Cells were plated at a density of $1 \times 10^{6}$ cells/well in 6-well tissue culture plates. After treatment with each of the indicated reagents, total RNA was obtained with an assayBLUE $^{\mathrm{TM}}$ total RNA extraction reagent (Intron Biotechnology, Sungnam, Korea). After determination of the amounts of the total RNA in each sample followed by electrophoresis on a formaldehyde-agarose gel, cDNA synthesis was performed using M-MLV reverse transcriptase (Rexgene, Ochang, Korea) as reported previously ${ }^{[14]}$. Polymerase chain reaction (PCR) was then conducted using Premix (Rexgene, Ochang, Korea) in a $20 \mu \mathrm{L}$ reaction that contained $2 \mu \mathrm{L}$ of reaction buffer, $1 \mu \mathrm{L}$ of $5 \mathrm{mmol} / \mathrm{L}$ dNTPs, $1 \mu \mathrm{L}$ of forward and reverse primer and $1 \mu \mathrm{L}$ of cDNA as the template, as reported previously ${ }^{[15]}$. The primer sequences are shown in Table 1.

\section{Immunoblotting}

Cells were lysed in PRO-PREP (Intron Biotechnology, Sungnam, Korea), after which the protein concentrations were quantified using a Bio-Rad protein assay (Bio-Rad, Hercules, CA, USA). Next, the lysates were boiled for $5 \mathrm{~min}$, after which $20 \mu \mathrm{g}$ of each total protein was subjected to SDS-polyacrylamide gel electrophoresis (PAGE) on $12 \%$ slab gels. The proteins were then transferred to polyvinylidene difluoride membranes (PVDF, Millipore, Bedford, MA, USA), which were subse-

Table 1. The sequence of primers used.

\begin{tabular}{|c|c|c|}
\hline Gene & & Sequences \\
\hline \multirow[t]{2}{*}{ GAPDH } & $\mathrm{F}$ & 5'-AAGGGTCATCATCTCTGCCC-3' \\
\hline & $\mathrm{R}$ & 5'-GTGATGGCATGGACTGTGGT-3' \\
\hline \multirow[t]{2}{*}{ PIMT } & $\mathrm{F}$ & 5'-TCAGGAAGGACGATCCAACA-3' \\
\hline & $\mathrm{R}$ & 5'-TCCTCCGGGCTTTAACTGAT-3' \\
\hline \multirow[t]{2}{*}{ Fibronectin } & $\mathrm{F}$ & 5'-ATTCCGGGTGGAATATGAGC-3' \\
\hline & $\mathrm{R}$ & 5'-CTGCTCCAGCGAACAACAAT-3' \\
\hline \multirow[t]{2}{*}{ TGF- $\beta 1$} & $\mathrm{~F}$ & 5'-GAGGGGAAATTGAGGGCTTT-3' \\
\hline & $\mathrm{R}$ & 5'-CGGTAGTGAACCCGTTGATC-3' \\
\hline \multirow[t]{2}{*}{ MMP-2 } & $\mathrm{F}$ & 5'-AATGCCATCCCCGATAACC-3' \\
\hline & $\mathrm{R}$ & 5'-AAACTTCACGCTCTTCAGAC-3' \\
\hline \multirow[t]{2}{*}{ MMP-9 } & $\mathrm{F}$ & 5'-TCTTCCAGTACCGAGAGAAA-3' \\
\hline & $\mathrm{R}$ & 5'-AGGATGTCATAGGTCATAGGT-3' \\
\hline \multirow[t]{2}{*}{ Snail } & $\mathrm{F}$ & 5'-GGGCAGGTATGGAGAGGAAG-3' \\
\hline & $\mathrm{R}$ & 5'-TTCTTCTGCGCTACTGCTGC-3' \\
\hline \multirow[t]{2}{*}{ Slug } & $\mathrm{F}$ & 5'-CCTGGTCAAGAAGCATTTCA-3' \\
\hline & $\mathrm{R}$ & 5'-GCCCCAAAGATGAGGAGTAT-3' \\
\hline \multirow[t]{2}{*}{ Integrin $\alpha v$} & $\mathrm{~F}$ & 5'-GTTGGGAGATTAGACAGAGG-3' \\
\hline & $\mathrm{R}$ & 5'-CAAAACAGCCAGTAGCAACA-3' \\
\hline \multirow[t]{2}{*}{ E-cadherin } & $\mathrm{F}$ & 5'-CAGCACGTACACAGCCCTAA-3' \\
\hline & $\mathrm{R}$ & 5'-GCTGGCTCAAGTCAAAGTCC-3' \\
\hline
\end{tabular}


quently blocked for $2 \mathrm{~h}$ in TBS containing $0.5 \%$ Tween-20 and $5 \%(w / v)$ dry skim milk powder and then incubated overnight with primary antibodies as reported previously ${ }^{[16,17]}$. The membranes were then washed with TBS-T and incubated for $2 \mathrm{~h}$ with HRP-linked anti-rabbit IgG (Millipore, Bedford, MA, USA) or HRP-linked anti-mouse IgG (Millipore, Bedford, MA, USA) secondary antibody. For chemiluminescence detection, the probed blots were incubated for 5 min with Immobilon Western HRP substrate (Millipore, Bedford, MA, USA) as reported previously ${ }^{[18,19]}$.

\section{siRNA transfection}

To conduct PIMT siRNA transfection, $4 \times 10^{5}$ cells per well were seeded in 6-well plates and then incubated for $48 \mathrm{~h}$ at $37^{\circ} \mathrm{C}$ in medium containing serum, which allowed the cells to become approximately $80 \%$ confluent. A mixture of PIMT siRNA and Lipofectamine $^{\mathrm{TM}}$ RNAiMAX (Invitrogen, Carlsbad, CA, USA) was prepared prior to treatment as reported previously ${ }^{[20]}$. Briefly, the Lipofectamine ${ }^{\mathrm{TM}}$ RNAiMAX was incubated with siRNA in OPTI-MEM (Gibco, Gaithersburg, MD, USA) at room temperature for $30 \mathrm{~min}$. The cells were then incubated in this mixture for $48 \mathrm{~h}$ at $37^{\circ} \mathrm{C}$ in a fresh culture medium containing serum.

\section{Gelatin zymography}

Gelatin zymography was performed for semiquantitative analysis of the gelatinase activities of conditioned media secreted from detached human breast cancer cells as previously described by Gottschall and $\mathrm{Yu}^{[21]}$, with slight modifications $^{[22]}$. Briefly, samples of the culture media were mixed with non-reducing sample buffer [5\% w/v SDS, 20\% glycerol, $0.5 \mathrm{~mol} / \mathrm{L}$ Tris- $\mathrm{HCl}(\mathrm{pH}$ 6.8) and 1\% bromophenol blue] and then separated by electrophoresis for $1 \mathrm{~h}$ at $150 \mathrm{~V}$ on $7.5 \%$ to $10 \%$ polyacrylamide gel containing $0.1 \%$ SDS and $1.5 \mathrm{mg} / \mathrm{mL}$ gelatin. Next, the gels were washed twice with $2.5 \%$ Triton X-100 for $30 \mathrm{~min}$ to remove the SDS and then incubated for $24 \mathrm{~h}$ at $37{ }^{\circ} \mathrm{C}$ with developing buffer $(50 \mathrm{mmol} / \mathrm{L}$ Tris- $\mathrm{HCl}$, $5 \mathrm{mmol} / \mathrm{L} \mathrm{CaCl}_{2}, \mathrm{pH}$ 7.6). The gels were then stained with Coomassie Brilliant Blue R-250 (0.1\% Coomassie Brilliant Blue, $40 \%(v / v)$ methanol, and 10\% (v/v) acetic acid) for 30 to $60 \mathrm{~min}$, after which the gels were destained with $10 \%(v / v)$ acetic acid /20\% (v/v) methanol. The gelatinolytic activities were then visualized as a white band against to the uniformly stained background.

\section{Wound healing assay}

The method for our wound closure assay was modified as reported previously ${ }^{[23,24]}$. Briefly, cells were grown to confluence in 24-well-plates. A control group was cultured in DMEM supplemented with $10 \%$ FBS, and the experimental group was transfected with PIMT siRNA. After the cells grew into full confluency, the medium was aspirated, and a wound was scraped on the cell monolayer using a $200 \mu \mathrm{L}$ micropipette tip. The wounded culture plates were then incubated for $24 \mathrm{~h}$ at $37^{\circ} \mathrm{C}$. The migration of cells into the scraped area was eval- uated using a bright field microscope and then photographed by digital photography (Canon, Japan).

\section{Statistical analysis}

A student's $t$-test and a one-way ANOVA were used to determine the statistical significance of differences between values for the various experimental and control groups. Data are expressed as mean \pm standard errors (SEM) and the results are taken from at least three independent experiments performed in triplicate. $P$ values of 0.05 or less were considered to be statistically significant.

\section{Results}

Cell detachment leads to EMT-like changes of MDA-MB 231 cells Cell detachment from the ECM suppresses anoikis, allowing these tumor cells to survive and proliferate in the body; however, these cells must eventually resettle in the substratum at a different site ${ }^{[25]}$. Indeed, detached cells $(\mathrm{d})$ reattached to the culture dish at a much faster rate than attached cells (a) and exhibited a spindle-like morphology (Figure 1A). Indeed, detached-reattached cells exhibited morphologically changed pattern at $1 \mathrm{~h}$ incubation up to 4-fold (Figure 1A, right panel). To determine if the change in the morphology of the detached cancer cells represents EMT, the mRNA and protein levels of several EMT-specific proteins were evaluated. The expression levels of integrin av, fibronectin, TGF- $\beta 1$, and MMP-2 were all strikingly increased (Figure $1 \mathrm{~B}$ and $1 \mathrm{C}$ ). Furthermore, the transcription factors Snail and Slug, known to repress E-cadherin, a suppressor of invasion during carcinoma progression $^{[26]}$, were highly upregulated in the detached cells up to 3 to 10 folds (Figure 1B). In agreement with expression level tests, MMP-2 activity (72 kDa) occurred prominently only in detached cells grown in conditioned media (CM).

\section{ERK is a critical enzyme involved in the regulation of EMT proteins in MDA-MB 231 cells}

To evaluate a regulatory pathway controlling EMT and EMT protein expression, the activated (phosphorylated) forms of several enzymes were investigated using detached cells. Of tested proteins, the levels of phospho-ERK1/2 and phosphoMEK1/2 were increased in a time-dependent manner, while phospho-AKT1 appeared at $1 \mathrm{~h}$ and was maintained at similar levels for up to $6 \mathrm{~h}$. Additionally, the levels of phospho-GSK3 decreased in a time-dependent manner (Figure 2A, left panel).

To confirm this pattern, selective inhibitors of ERK kinase (PD98059, $25 \mu \mathrm{mol} / \mathrm{L}$ ) and the activator of GSK3 ( $\mathrm{LiCl}, 2$ $\mu \mathrm{mol} / \mathrm{L})$ were employed, and the mRNA levels of EMT proteins or EMT-regulatory proteins were then determined. As Figure 2B shows, $\mathrm{LiCl}$ enhanced phospho-GSK3 levels, and PD98059 blocked the phosphorylation of ERK1/2, indicating that the drugs were functioning. As expected, PD98059 suppressed the mRNA expression of the EMT proteins. In contrast, the induction effect by $\mathrm{LiCl}$ was only observed in fibronectin expression assays. PD98059 also suppressed the activity of MMP-2 (Figure 2D). 

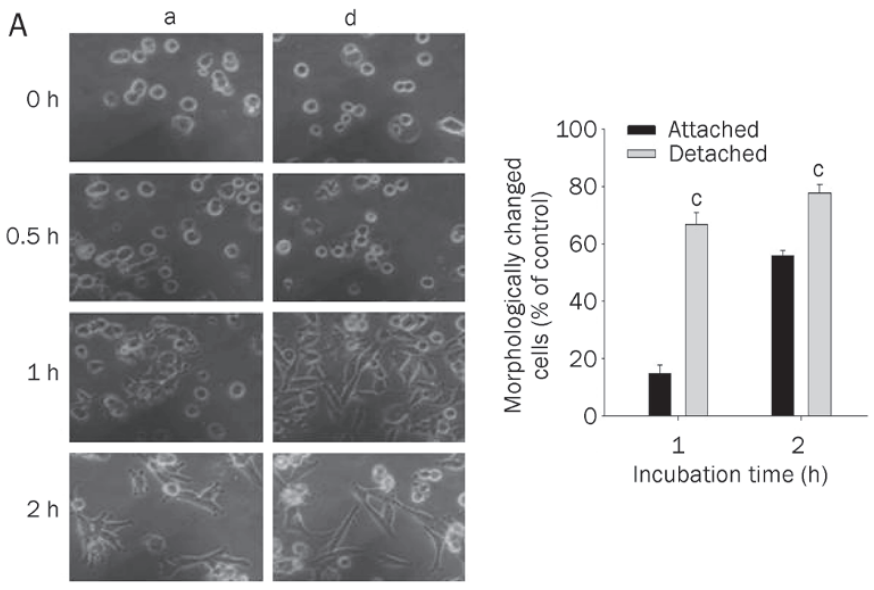

B

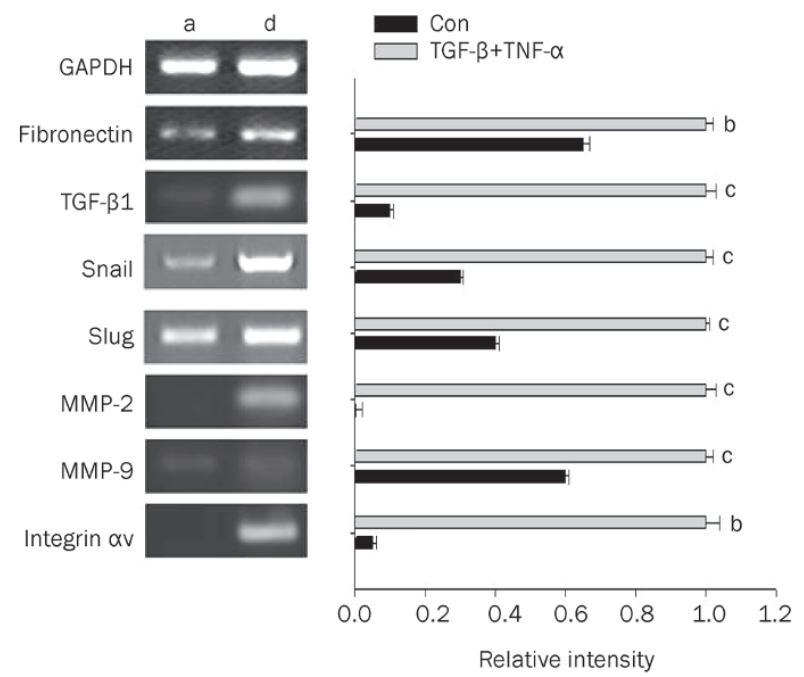

C

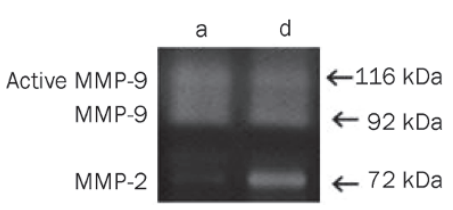

Figure 1. Cell detachment led to an EMT-like change and increased PIMT expression. (A) Detached (d) MDA-MB-231 cells (10 6 cells/well $\times 6$ wells) were maintained in suspension on poly-HEMA or were allowed to attach (a) to culture dishes in serum-free media for $24 \mathrm{~h}$. The cells were then treated with $0.025 \%$ trypsin $0.02 \mathrm{mmol} / \mathrm{L}$ EDTA and re-attached to the culture plates. The images were taken by a digital camera at the indicated time after seeding. (B) Effect of detachment on the mRNA expression of the mesenchymal markers fibronectin, TGF- $\beta 1$, Snail, Slug, MMP-2, MMP-9, and integrin $\alpha v$ in MDA-MB-231 cells were examined by RT-PCR. (C) Effect of detachment on the activity of MMPs from human breast cancer cells. Attached and detached cells were incubated for $24 \mathrm{~h}$, and the conditioned media (CM) from each group was harvested after one day of incubation in serum-free media. The relative intensity of individual bands was calculated by using Syngene gel image analysis software. ${ }^{\mathrm{b}} P<0.05,{ }^{\mathrm{c}} P<0.01$ represent significant difference compared to each control group.

PIMT is a critical enzyme involved in the regulation of EMT proteins in MDA-MB 231 cells

To examine the importance of PIMT in the EMT, the expression of PIMT was measured. As Figure 3A shows, the mRNA and protein levels of PIMT were markedly increased in cells cultured on poly-HEMA-coated dishes compared to cells adhered to uncoated plastic dishes. Interestingly, levels of PIMT were clearly reduced by PD98059 treatment, whereas $\mathrm{LiCl}$ enhanced PIMT mRNA and protein levels (Figure 3B). These data suggest that ERK acts as a positive regulator, while GSK3 acts as a negative one, as reported previously ${ }^{[27]}$.

Knockdown of PIMT is linked to the suppression of EMT protein expression in MDA-MB 231 cells

To determine whether PIMT influences the expression of EMT proteins, siRNA targeting PIMT was introduced to detached MDA-MB-231 human breast cancer cells. Intriguingly, knockdown of PIMT led to blockade of the EMT-like transformation as well as suppression of the mRNA levels of PIMT, integrin av, fibronectin, and TGF- $\beta 1$ (Figure 4A). Conversely, RTPCR revealed that E-cadherin expression occurred in PIMTknockdown MDA-MB-231 cells (Figure 4A). Interestingly, PIMT depletion also induced the suppression of phospho-
ERK levels and the phosphorylation of p90RSK, a downstream enzyme of ERK, indicating that there may be a crossregulation between the PIMT and ERK pathways that affects the expression of these proteins in EMT.

Finally, to determine if PIMT is important for the conversion of stationary cells into motile cells capable of invasion through the $\mathrm{ECM}^{[2]}$, a wound healing migration assay was employed. As Figure 4C shows, PIMT siRNA-treated cells displayed a clear reduction in cell migration, suggesting that PIMT is indeed linked to cancer cell migration and invasion.

PIMT is up-regulated during the EMT of MDA-MB-231 cells triggered by cotreatment with TGF- $\beta$ and TNF- $\alpha$

During siRNA analysis, we found that PIMT expression was required for the EMT phenotype of MDA-MB-231 breast cancer cells in poly-HEMA-coated dishes. As such, we sought to determine if PIMT expression is up-regulated during the induction of EMT by TGF- $\beta$ and TNF- $\alpha$. Previously, treatment with a combination of TGF- $\beta$ and TNF- $\alpha$ was shown to induce EMT in some cell types ${ }^{[28]}$. Indeed, when MDA-MB-231 breast cancer cells were treated with TGF- $\beta /$ TNF- $\alpha$, a morphological change from an epithelial-like to a mesenchymal-like appearance was induced (Figure 5A). Additionally, TGF- $\beta$ / 
A

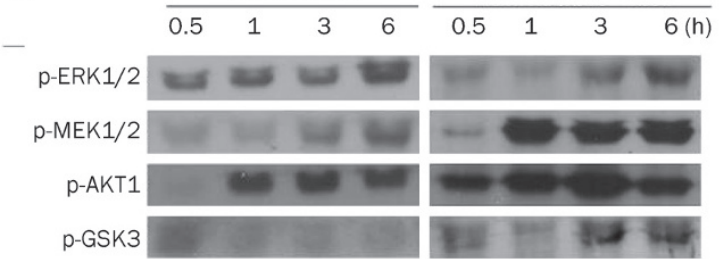

C
B

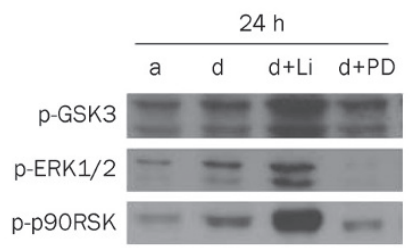

D

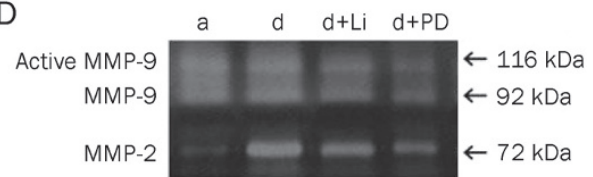

Figure 2. The ERK inhibitor PD98059 alters the expression of PIMT and EMT proteins. (A, B, and C) Detached (d) MDA-MB-231 cells ( $10^{6}$ cells/well $\times 6$ wells) were maintained in suspension on poly-HEMA in serum-free media for indicated times in media containing PD98059 (PD, $25 \mu \mathrm{mol} / \mathrm{L}$ ) or $\mathrm{LiCl}(\mathrm{Li}, 2 \mu \mathrm{mol} / \mathrm{L})$. After preparing whole lysates, the phosphorylation levels of ERK, MEK, Akt1, and GSK3 were analyzed by immunoblotting. (B) The phosphorylation levels of GSK3, ERK1/2, and p90RSK were determined by immunoblotting analysis of detached MDA-MB-231 cells $\left(10^{6}\right.$ cells/well $\times 6$ wells) cultured on poly-HEMA in the presence or absence of PD98059 $(25 \mu \mathrm{mol} / \mathrm{L})$ or LiCl $(2 \mu \mathrm{mol} / \mathrm{L})$ for $24 \mathrm{~h}$. (C) The mRNA levels of fibronectin, TGF- $\beta 1$, Slug, MMP-2, and MMP-9 were analyzed by RT-PCR using detached MDA-MB- 231 cells $\left(10^{6}\right.$ cells/well $\times 6$ wells) cultured on poly-HEMA in the presence or absence of PD98059 $(25 \mu \mathrm{mol} / \mathrm{L})$ or $\mathrm{LiCl}(2 \mu \mathrm{mol} / \mathrm{L})$ for $24 \mathrm{~h}$. (D) The activity of MMP-2 and MMP-9 was examined by gelatin zymography using detached MDA-MB-231 cells ( $10^{6}$ cells/well $x 6$ wells) cultured on poly-HEMA in the presence or absence of PD98059 (25 $\left.\mu \mathrm{mol} / \mathrm{L}\right)$ or LiCl (2 $\left.\mu \mathrm{mol} / \mathrm{L}\right)$ for $24 \mathrm{~h}$.
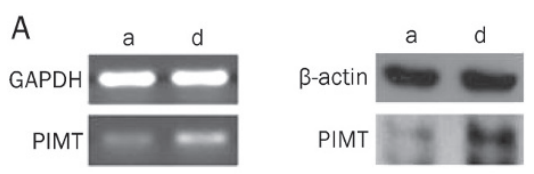

B
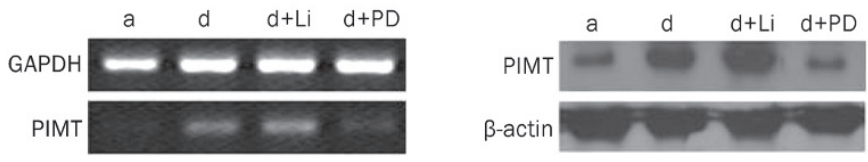

Figure 3. ERK1/2 activation regulates PIMT expression. (A) Detached (d) MDA-MB-231 cells $\left(10^{6}\right.$ cells/well $\times 6$ wells $)$ were maintained in a suspension on poly-HEMA or were allowed to attach (a) to culture dishes in serum free media for $24 \mathrm{~h}$. The mRNA and protein levels of PIMT were analyzed by RT-PCR and immunoblotting. (B) The mRNA and protein levels of PIMT were determined by RT-PCR and immunoblotting analysis of detached MDA-MB-231 cells $\left(10^{6}\right.$ cells/well $\times 6$ wells) cultured on polyHEMA in the presence or absence of PD98059 (PD, $25 \mu \mathrm{mol} / \mathrm{L}$ ) or $\mathrm{LiCl}(\mathrm{Li}$, $2 \mu \mathrm{mol} / \mathrm{L}$ ) for $24 \mathrm{~h}$.

TNF-a-treated MDA-MB-231 cells showed increased mRNA expression of EMT proteins such as integrin av, fibronectin, Snail, Slug, MMP-2, and MMP-9 as well as PIMT, up to 2 to 5 folds (Figure 5B). The protein levels of PIMT, integrin av, MMP-2, N-cadherin, phospho (p)-ERK, and p-GSK3 were also significantly upregulated by 2 to 5 folds during TGF- $\beta$ /TNF- a-induced EMT (Figure 5C).

\section{Discussion}

At the cellular level, one requirement of metastasis is that cells detach from their primary site and then migrate to the lymphatic and circulatory systems. In the absence of ECM attachment, cells undergo a form of apoptosis known as anoi$\mathrm{kis}^{[29]}$. It is thought that anoikis-resistant cells contribute to the epithelial-mesenchymal transition (EMT), which is one of the metastatic components that lead to a more flexible and migratory phenotype ${ }^{[30]}$. In an attempt to gain further insight into the biochemical features underlying the EMT, we selected anoikis-resistant cells by culturing the breast cancer cell line MDA-MB-231 on poly-HEMA-coated tissue culture plates. We found that detached MDA-MB-231 cells exhibited spindles and a lengthened morphology compared to attached cells (Figure 1A). This is phenotypically characteristic of the EMT. During this transition, mesenchymal cells acquire a morphology that is appropriate for both migration in an extracellular environment and interactions between epithelial and mesenchymal cells ${ }^{[31]}$. Our results also showed that detached MDAMB-231 cells expressed increased levels of metastatic factors such as integrin av and EMT proteins such as TGF- $\beta 1$, Snail, Slug, and MMP-2 (Figure 1B and 1C). All of these factors are important for tumor progression and metastasis, as they facilitate cell migration ${ }^{[32]}$.

It has been reported that ERK plays a critical role in the 
A

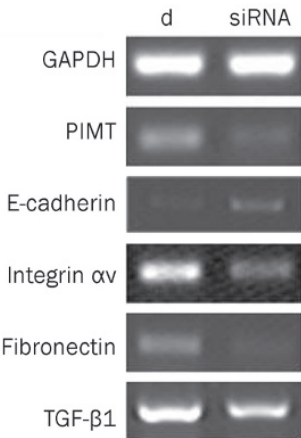

C

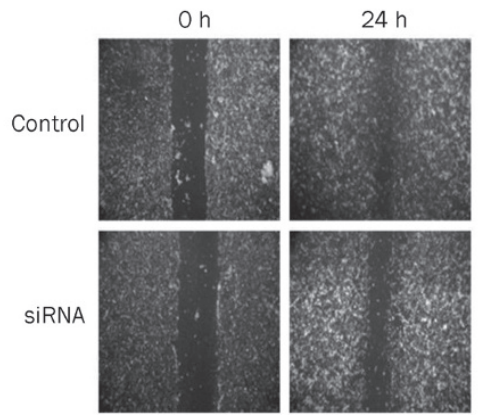

Figure 4. Depletion of PIMT results in the up-regulation of E-cadherin and the down-regulation of integrin $\alpha v$ and EMT proteins and inhibits cell migration. (A) Detached cells $\left(4 \times 10^{5}\right.$ cells/well $\times 6$ wells) were transfected with the indicated siRNA constructs for $48 \mathrm{~h}$. After preparing mRNA, the levels of PIMT, E-cadherin, integrin $\alpha v$, fibronectin, TGF- $\beta 1$, and GAPDH were determined by RT-PCR. (B) The phospho- or total levels of integrin $\alpha v$, ERK1/2, p90RSK, and $\beta$-actin were determined by immunoblotting analysis using PIMT siRNA-transfected cells after $48 \mathrm{~h}$. (C) After transient transfection of PIMT siRNA, wounds were introduced with 200 $\mu \mathrm{L}$ micropipette tips. After $24 \mathrm{~h}$ of incubation in $5 \% \mathrm{CO}_{2}$ atmosphere at $37{ }^{\circ} \mathrm{C}$ in a humidified incubator, the amount of wound recovery was photographed using a light microscope with $400 \times$ magnification for each group.

process of EMT ${ }^{[33,34]}$. During the course of our assays, phosphorylation of MEK1/2 and ERK was found to be increased in detached MDA-MB-231 cells (Figure 2A). The critical role of ERK in EMT process has been illustrated by treating cells with PD98059, a specific ERK inhibitor (Figure 2B). This compound strongly inhibited the expression of EMT proteins such as integrin av, fibronectin, Snail, Slug, and MMP-2 (Figure 2C), suggesting that ERK is crucial for the EMT. Although it is well known that ERK is functionally important for the survival of detached cells ${ }^{[35]}$, our results and those of others suggest that this enzyme plays a critical role throughout the entire EMT, promoting morphological changes, migration, and adhesiveness. In addition, ERK inhibition has been reported to strongly suppress the migration of various cancer cells and the homotypic cell-cell adhesion induced by integrins ${ }^{[13,36,37]}$.

Under our conditions, PIMT expression was also markedly increased in detached cells compared to attached MDAMB-231 cells (Figure 3A). Similar findings have been reported in other nonattached HUVEC, Caki-1, and U-87 cells ${ }^{[9]}$.
A

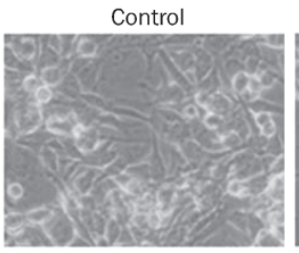
$T G F-\beta+T N F-\alpha$

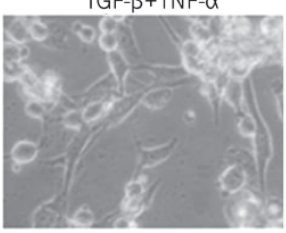

B

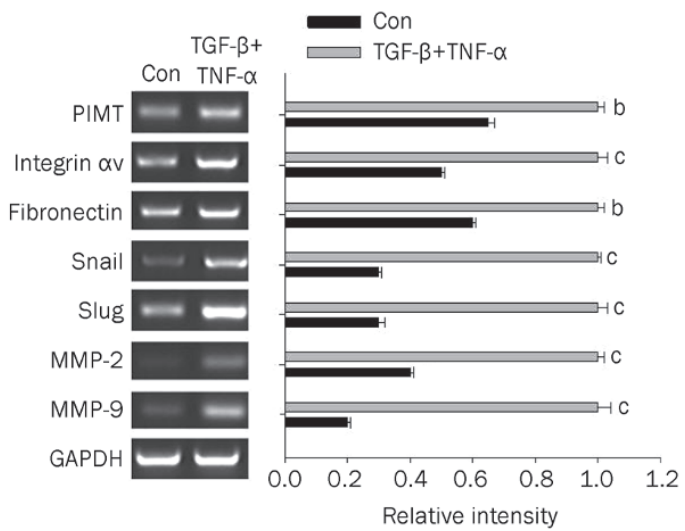

C

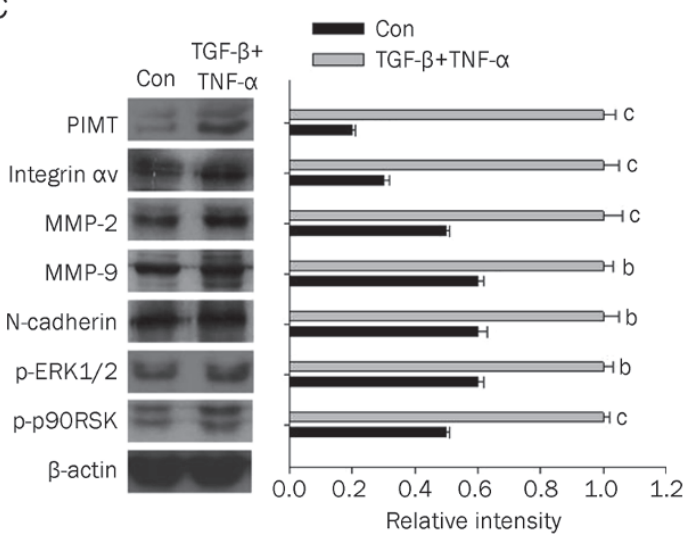

Figure 5. TGF- $\beta /$ TNF- $\alpha$ treatment increases ERK1/2 phosphorylation and PIMT expression. (A) Cells were treated with a combination of TGF- $\beta$ $(10 \mathrm{ng} / \mathrm{mL})$ and TNF- $\alpha(10 \mathrm{ng} / \mathrm{mL})$ for $48 \mathrm{~h}$ and then examined by phasecontrast microscopy. ( $B$ and $C$ ) MDA-MB-231 cells were incubated for $48 \mathrm{~h}$ with TGF- $\beta /$ TNF- $\alpha$, and the mRNA and protein levels of PIMT, integrin $\alpha v$, fibronectin, Snail, Slug, MMP-2, MMP-9, N-cadherin, p-ERK1/2, and p-p90RSK were determined by RT-PCR and immunoblotting analysis. The relative intensity of individual bands was calculated by using Syngene gel image analysis software. ${ }^{\mathrm{b}} P<0.05,{ }^{\mathrm{c}} P<0.01$ represent significant difference compared to each control group.

Interestingly, the protein and mRNA levels of PIMT were reduced upon exposure to the ERK inhibitor PD98059 (Figure 3B), indicating that ERK is biochemically important for PIMT synthesis. Interestingly, siRNA targeting PIMT suppressed various EMT proteins in addition to ERK phosphorylation, suggesting that PIMT possesses a critical function in the biochemical regulation of EMT proteins. Furthermore, PIMT siRNA treatment also resulted in diminished cell migration, as assessed by a wound healing assay (Figure 4C). Up-regulation of PIMT was also observed in TGF- $\beta /$ TNF- $\alpha$-stimulated EMT 
conditions exhibiting enhanced levels of integrin av, Snail, Slug, MMP-2, and MMP-9 (Figure 5), up to 2 to 5 folds, as reported previously ${ }^{[38]}$. Additionally, it has been reported that PIMT possesses a potential anti-apoptotic function in Baxoverexpressing cells ${ }^{[39]}$. Considering these findings, enhanced levels of PIMT appear to be essential for the survival of detached cells. This protein likely influences the early events of anoikis and migration, both of which are regulated by EMT proteins and ERK activity. We cannot, however, rule out the possibility that PIMT is functioning as a repair enzyme ${ }^{[40]}$, although the involvement or appearance of aged proteins or isoaspartyl residues in the signaling cascade required for EMT protein synthesis was not verified. Surprisingly, it has been observed that valproic acid and lithium, used for the treatment of epileptic seizures and mania in bipolar disorder, have both been shown to simultaneously upregulate the ERK pathway and PIMT induction ${ }^{[27,41]}$. These results suggest that the activation and expression of ERK pathway members and PIMT could be tightly associated. As it remains unclear how ERK and PIMT co-regulate the EMT, our future experiments will focus on understanding this cross-regulation mechanism.

Numerous lines of evidence indicate that EMT is able to impose cancer cells into self-renewal cancer stem-like cells to spawn macroscopic metastases ${ }^{[42,43]}$. EMT-based tumor metastatic events include cell migration requiring for embryonic development and wound healing managed by adult stem cells $^{[44]}$. Therefore, it could be interesting to determine whether our EMT conditions are capable of transforming MDA-MB-231 cells into highly metastatic stem-like cells. To do this, phenotype of these cells will be determined by measuring the surface levels of CD $44 / \mathrm{CD} 24^{[45]}$.

Taken together, the results presented here provide in vitro support for the idea that PIMT and ERK are tightly expressed and activated in EMT conditions generated during the detachment of MDA-MB-231 cells from poly-HEMA coated dishes and by TGF- $\beta$ /TNF- $\alpha$ stimulation, as summarized in Figure 6. These findings suggest that the development of specific inhibitors of PIMT may lead to a novel route of inhibition of the EMT and metastasis.

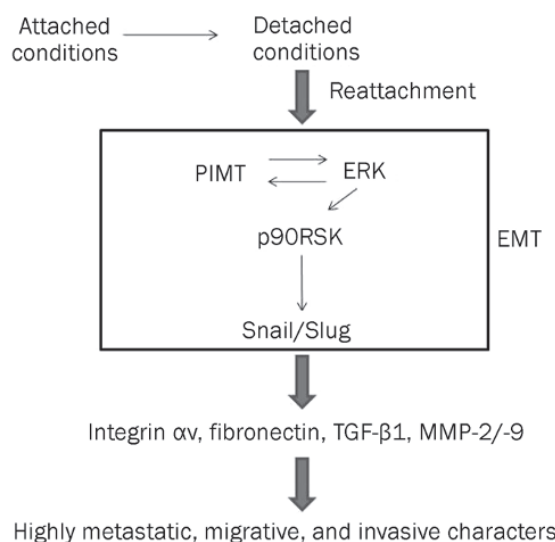

Figure 6. Schematic diagram of EMT process of MDA-MD-231 cells induced by detachment and reattachment conditions.

\section{Abbreviations}

ECM, extracellular matrix; EMT, epithelial-mesenchymal transition; ERK1/2, extracellular signal-regulated kinase; GSK3, glycogen synthase kinase 3; MAPK, mitogen-activated protein kinase; MMP, matrix metalloproteinase; PIMT, protein $L$-isoaspartyl O-methyltransferase; $\mathrm{PI} 3 \mathrm{~K}$, phosphoinositide 3-kinase; TGF- $\beta$, transforming growth factor-beta; TNF-a, tumor necrosis factor-alpha.

\section{Acknowledgements}

This research was supported by Technology Development Program for Agriculture and Forestry, Ministry for Food, Agriculture, Forestry and Fisheries, Republic of Korea.

\section{Author contribution}

Jiyeon RYU and Sungyoul HONG designed research; Jiyeon RYU, Jihyeok SONG, Jieun HEO and Yongwoo JUNG performed research; Jiyeon RYU, Sang-Jin LEE, Jae Youl CHO, and Sungyoul HONG analyzed data; Jae Youl CHO and Sungyoul HONG wrote the paper.

\section{References}

1 Creighton CJ, Chang JC, Rosen JM. Epithelial-mesenchymal transition (EMT) in tumor-initiating cells and its clinical implications in breast cancer. J Mammary Gland Biol Neoplasia 2010; 15: 253-60.

2 Yang J, Weinberg RA. Epithelial-mesenchymal transition: at the crossroads of development and tumor metastasis. Dev Cell 2008; 14: 818-29.

3 Do Kwon Y, Bin Noh H, Ahn HJ, Lee WJ, Kwack K. The molecular signature of in vitro senescence in human mesenchymal stem cells. Genes Genom 2010; 32: 87-93.

4 Gotzmann J, Mikula M, Eger A, Schulte-Hermann R, Foisner R, Beug $\mathrm{H}$, et al. Molecular aspects of epithelial cell plasticity: implications for local tumor invasion and metastasis. Mutat Res 2004; 566: 9-20.

5 Smalley KS, Brafford PA, Herlyn M. Selective evolutionary pressure from the tissue microenvironment drives tumor progression. Semin Cancer Biol 2005; 15: 451-9.

6 Shimizu T, Matsuoka Y, Shirasawa T. Biological significance of isoaspartate and its repair system. Biol Pharm Bull 2005; 28: 1590-6.

7 Reissner KJ, Aswad DW. Deamidation and isoaspartate formation in proteins: unwanted alterations or surreptitious signals? Cell Mol Life Sci 2003; 60: 1281-95.

8 Lanthier J, Desrosiers RR. Protein L-isoaspartyl methyltransferase repairs abnormal aspartyl residues accumulated in vivo in type-I collagen and restores cell migration. Exp Cell Res 2004; 293: 96-105.

9 Lanthier J, Desrosiers RR. Regulation of protein L-isoaspartyl methyltransferase by cell-matrix interactions: involvement of integrin alphavbeta3, PI3-kinase, and the proteasome. Biochem Cell Biol 2006; 84: 684-94.

10 Johnson-Holiday C, Singh R, Johnson E, Singh S, Stockard CR, Grizzle $\mathrm{WE}$, et al. CCL25 mediates migration, invasion and matrix metalloproteinase expression by breast cancer cells in a CCR9-dependent fashion. Int J Oncol 2011; 38: 1279-85.

11 Garrido T, Riese HH, Aracil M, Perez-Aranda A. Endothelial cell differentiation into capillary-like structures in response to tumour cell conditioned medium: a modified chemotaxis chamber assay. $\mathrm{Br} J$ Cancer 1995; 71: 770-5. 
12 Hunakova L, Sedlakova O, Cholujova D, Gronesova P, Duraj J, Sedlak J. Modulation of markers associated with aggressive phenotype in MDAMB-231 breast carcinoma cells by sulforaphane. Neoplasma 2009; 56: 548-56.

13 Cho JY, Fox DA, Horejsi V, Sagawa K, Skubitz KM, Katz DR, et al. The functional interactions between CD98, beta1-integrins, and CD147 in the induction of U937 homotypic aggregation. Blood 2001; 98 : 374-82.

14 Rhee DK, Kim EH, Lee MJ, Kim IH, Pyo S, Choi KT. Anti-apoptotic effects of red ginseng on oxidative stress induced by hydrogen peroxide in SK-N-SH cells. J Ginseng Res 2010; 34: 138-44.

15 Lee YH, Hong JK, Kim JS, Kim JA, Lee SI, Lim MH, et al. Identification and characterization of $\mathrm{SHI}$ family genes from Brassica rapa $\mathrm{L} \mathrm{ssp}$ pekinensis. Genes Genom 2010; 32: 309-17.

16 Xing P, Li JG, Jin F, Zhao TT, Liu Q, Dong HT, et al. Fascin, an actinbundling protein, promotes breast cancer progression in vitro. Cell Biochem Funct 2011; 29: 303-10.

17 Park JK, Do Kim H, Ha SE, Kang JR. Effect of Korean red ginseng extract on cell death responses in peroxynitrite-treated keratinocytes. J Ginseng Res 2010; 34: 205-11.

18 Tsuchiyama J, Imajo K, Yoshino T, Nanba N, Toyota A, Yoshida C, et al. High-dose chemotherapy and autologous peripheral blood stem cell transplantation for treatment of unspecified peripheral T-cell lymphoma presented with hepatosplenomegaly and hypercytokinemia syndrome: report of three cases. Ann Hematol 2002; 81: 588-92.

19 Chun YJ, Shim JH, Choi CS, Lee EC, Kim MY. Tamoxifen suppresses clusterin level through Akt inactivation and proteasome degradation in human prostate cancer cells. Biomol Ther 2009; 17: 25-31.

20 Chun YJ, Lee HM, Surh BY. Roles of neutral sphingomyelinase 1 on CD95-mediated apoptosis in human Jurkat T lymphocytes. Biomol Ther 2010; 18: 262-70.

21 Gottschall PE, YU X. Cytokines regulate gelatinase A and B (matrix metalloproteinase 2 and 9 ) activity in cultured rat astrocytes. J Neurochem 1995; 64: 1513-20.

22 Moon A, Kim JS. Fibronectin induces Pro-MMP-2 activation and enhances invasion in H-Ras-transformed human breast epithelial cells. Biomol Ther 2009; 17: 288-92.

23 Nobes CD, Hall A. Rho GTPases control polarity, protrusion, and adhesion during cell movement. J Cell Biol 1999; 144: 1235-44.

24 Kang TJ, Lee GS, Choi JY, Choi YJ, Yim DS, Cheong JH. The wound healing effect of Hydnocarpi Semen extract on ulcer in diabetic mice. Biomol Ther 2010; 18: 329-35.

25 Haraguchi M, Okubo T, Miyashita Y, Miyamoto Y, Hayashi M, Crotti $\mathrm{TN}$, et al. Snail regulates cell-matrix adhesion by regulation of the expression of integrins and basement membrane proteins. J Biol Chem 2008; 283: 23514-23.

26 Larriba MJ, Martin-Villar E, Garcia JM, Pereira F, Pena C, de Herreros AG, et al. Snail2 cooperates with Snail1 in the repression of vitamin D receptor in colon cancer. Carcinogenesis 2009; 30: 1459-68.

27 Lamarre M, Desrosiers RR. Up-regulation of protein L-isoaspartyl methyltransferase expression by lithium is mediated by glycogen synthase kinase-3 inactivation and beta-catenin stabilization. Neuropharmacology 2008; 55: 669-76.

28 Arima Y, Inoue Y, Shibata T, Hayashi H, Nagano O, Saya H, et al. Rb depletion results in deregulation of E-cadherin and induction of cellular phenotypic changes that are characteristic of the epithelial-tomesenchymal transition. Cancer Res 2008; 68: 5104-12.
29 Kim JB, Yu JH, Ko E, Lee KW, Song AK, Park SY, et al. The alkaloid berberine inhibits the growth of Anoikis-resistant MCF-7 and MDAMB-231 breast cancer cell lines by inducing cell cycle arrest. Phytomedicine 2010; 17: 436-40.

30 Savagner P. The epithelial-mesenchymal transition (EMT) phenomenon. Ann Oncol 2010; 21: vii89-vii92.

31 Thiery JP. Epithelial-mesenchymal transitions in tumour progression. Nat Rev Cancer 2002; 2: 442-54.

32 Manes T, Zheng DQ, Tognin S, Woodard AS, Marchisio PC, Languino LR. Alpha(v)beta3 integrin expression up-regulates cdc2, which modulates cell migration. J Cell Biol 2003; 161: 817-26.

33 Chou TY, Chen WC, Lee AC, Hung SM, Shih NY, Chen MY. Clusterin silencing in human lung adenocarcinoma cells induces a mesenchymal-to-epithelial transition through modulating the ERK/Slug pathway. Cell Signal 2009; 21: 704-11.

34 Kuo PL, Chen YH, Chen TC, Shen KH, Hsu YL. CXCL5/ENA78 increased cell migration and epithelial-to-mesenchymal transition of hormone-independent prostate cancer by early growth response-1/ Snail signaling pathway. J Cell Physiol 2010; 226: 1224-31.

35 Gollob JA, Wilhelm S, Carter C, Kelley SL. Role of Raf kinase in cancer: therapeutic potential of targeting the Raf/MEK/ERK signal transduction pathway. Semin Oncol 2006; 33: 392-406.

36 Cho JY, Skubitz KM, Katz DR, Chain BM. CD98-dependent homotypic aggregation is associated with translocation of protein kinase Cdelta and activation of mitogen-activated protein kinases. Exp Cell Res 2003; 286: 1-11.

37 Stahle M, Veit C, Bachfischer U, Schierling K, Skripczynski B, Hall A, et al. Mechanisms in LPA-induced tumor cell migration: critical role of phosphorylated ERK. J Cell Sci 2003; 116: 3835-46.

38 Gal A, Sjoblom T, Fedorova L, Imreh S, Beug H, Moustakas A. Sustained TGF beta exposure suppresses Smad and non-Smad signalling in mammary epithelial cells, leading to EMT and inhibition of growth arrest and apoptosis. Oncogene 2008; 27: 1218-30.

39 Huebscher KJ, Lee J, Rovelli G, Ludin B, Matus A, Stauffer D, et al. Protein isoaspartyl methyltransferase protects from Bax-induced apoptosis. Gene 1999; 240: 333-41.

40 Furuchi T, Sakurako K, Katane M, Sekine M, Homma H. The role of protein L-isoaspartyl/D-aspartyl O-methyltransferase (PIMT) in intracellular signal transduction. Chem Biodivers 2010; 7: 1337-48.

41 Cournoyer P, Desrosiers RR. Valproic acid enhances protein L-isoaspartyl methyltransferase expression by stimulating extracellular signal-regulated kinase signaling pathway. Neuropharmacology 2009; 56: 839-48.

42 Alison MR, Lim SM, Nicholson LJ. Cancer stem cells: problems for therapy? J Pathol 2011; 223: 147-61.

43 Kong D, Banerjee S, Ahmad A, Li Y, Wang Z, Sethi S, et al. Epithelial to mesenchymal transition is mechanistically linked with stem cell signatures in prostate cancer cells. PLoS One 2010; 5: e12445.

44 Kondo M, Wagers AJ, Manz MG, Prohaska SS, Scherer DC, Beilhack GF, et al. Biology of hematopoietic stem cells and progenitors: implications for clinical application. Annu Rev Immunol 2003; 21 : 759-806.

45 Bhat-Nakshatri P, Appaiah H, Ballas C, Pick-Franke P, Goulet R Jr, Badve S, et al. SLUG/SNAI2 and tumor necrosis factor generate breast cells with $C D 44^{+} / C D 24^{-}$phenotype. BMC Cancer 2010; 10 : 411. 